\title{
Persepsi pada Bystander terhadap Intensitas Bullying pada Siswa SMP
}

\author{
Andi Halimah", Asniar Khumas ${ }^{2}$, Kurniati Zainuddin \\ Fakultas Psikologi Universitas Negeri Makassar
}

\begin{abstract}
This study aimed to determine the role of bystander onto intensity of bullying against students of junior high school in Makassar. The subjects of the study were 48 students aged 11-15 years old who were bullying perpetrators. The scales used for collecting data were bystanders' perception scale bullying intensity scale. The data were analyzed using simple regression analysis techniques. The results of the analysis showed that bystanders' perceptions could increase the intensity of bullying with $r=0,343$ and significant $p 0,017$. However, the effective contribution was $11.8 \%$. It could be concluded that the role of people present at the scene of bullying can increase its intensity or increase the likelihood of recurrence of it among the students. The concept of student-friendly school needs urgently to be applied. All stakeholders concerned with education and morality shaping of students must work together to realize this ideal.
\end{abstract}

Keywords: bystanders' perception, bullying intensity, junior high school students

Abstrak. Penelitian ini bertujuan untuk mengetahui peran bystander terhadap intensitas bullying pada siswa SMP di Makassar. Sebanyak 48 siswa pelaku bullying berusia 11-15 tahun menjadi subjek penelitian. Skala yang digunakan untuk mengumpulkan data adalah skala persepsi pada bystander dan skala intensitas bullying. Data penelitian dianalisis dengan teknik analisis regresi. Hasil analisis menunjukkan bahwa terdapat pengaruh positif persepsi pada bystander terhadap intensitas bullying dengan nilai $r$ sebesar 0,343 dan signifikansi atau $p$ sebesar 0,017. Adapun nilai sumbangan efektif sebesar $11,8 \%$. Dengan demikian, peran orang yang hadir di lokasi terjadinya bullying dapat meningkatkan intensitas atau meningkatkan kemungkinan berulangnya perilaku bullying pada siswa SMP di Makassar. Konsep sekolah yang ramah pada siswa merupakan hal yang sangat mendesak untuk diterapkan. Segenap stakeholder yang peduli dengan pendidikan dan pembentukan sikap mental atau akhlak peserta didik yang terpuji harus bersinergi untuk mewujudkan cita-cita mulia ini.

Kata kunci: persepsi pada bystander, intensitas bullying, siswa SMP

Salah satu perilaku siswa yang banyak diperbincangkan adalah perilaku bullying sebagai bentuk penindasan terhadap korban yang lemah dengan melakukan hal-hal yang tidak disukai secara berulang. Susanti (2006) mengemukakan

\footnotetext{
${ }^{1}$ Korespondensi mengenai isi artikel ini dapat dilakukan melalui: andikace@yahoo.co.id,

2 Atau melalui: hafizhdzaky@yahoo.com
}

bahwa bullying berasal dari kata bully yang artinya penggertak, orang yang mengganggu orang lain yang lebih lemah. Beberapa istilah dalam Bahasa Indonesia yang sering dipakai untuk menggambarkan fenomena bullying di antaranya adalah penindasan, 'penggencetan', 'perpeloncoan', 'pemalakan', pengucilan, dan intimidasi. Riauskina dkk. (2005) melakukan 
penelitian pada beberapa SMA di Jakarta dan Bogor, menemukan fakta bahwa bullying sudah menjadi tradisi siswa-siswi di SMA tersebut. Penelitian ini mencatat bahwa 'penggencetan' oleh kakak kelas pada adik kelas dapat dikategorikan menjadi dua jenis yaitu memarahi dan mengganggu. Adik kelas dimarahi ketika kakak kelas tidak suka, dan adik kelas diganggu ketika kakak kelas sedang ingin 'iseng'. Kondisi tersebut dapat membuat lingkungan sekolah menjadi tempat lahirnya preman-preman. Penelitian yang dilakukan Simbolon (2012) menemukan bahwa fenomena bullying masih ditemukan berlanjut hingga tingkat universitas. Mahasiswa asrama yang terlibat dalam penelitian tersebut mengaku telah menindas dengan memukul dan melecehkan korban yang merupakan juniornya bahkan pelaku mengaku telah memaksa korban menenggak minuman keras dan menelanjangi lalu memaksanya mandi di tengah malam.

Data kasus bullying di Amerika dilaporkan oleh Josephson Institute of Ethics yang telah melakukan survei pada 43000 remaja, hasilnya $47 \%$ remaja berusia 15 hingga 18 tahun telah mengalami bullying dan $50 \%$ dari remaja tersebut telah mengganggu, menggoda, dan mengejek siswa lain. National Association of Elementary School Principals (2013) melaporkan bahwa setiap tujuh menit anak dibully di lingkungan sekolah, dan setiap bulan ada tiga juta murid absen dari sekolah karena merasa tidak nyaman. Diperkirakan ada 18 juta anak telah dibully di tahun 2013.

Anak sebagai peserta didik berhak memperoleh pendidikan dalam lingkungan yang aman dan bebas dari rasa takut. Di Indonesia, hal tersebut diatur dalam Undang-Undang Perlindungan Anak (UUPA) Nomor 23 Tahun 2002 pasal 54 menyatakan, "Anak di dalam dan di lingkungan sekolah wajib dilindungi dari tindakan kekerasan yang dilakukan oleh guru, pengelola sekolah atau teman-temannya di dalam sekolah yang bersangkutan, atau lembaga pendidikan lainnya".

Bullying merupakan perilaku yang tidak bisa diterima secara sosial. Hasil studi oleh ahli intervensi bullying, Huneck (2007) mengungkapkan bahwa $10-60 \%$ siswa di Indonesia melaporkan telah mendapat ejekan, cemoohan, pengucilan, pemukulan, tendangan, atau dorongan, sekurangkurangnya sekali dalam seminggu. Di Indonesia, kasus bullying di sekolah menduduki peringkat teratas pengaduan masyarakat ke Komisi Perlindungan Anak Indonesia (KPAI) di sektor pendidikan. Dari 2011 sampai Agustus 2014, KPAI mencatat 369 pengaduan terkait masalah tersebut. Jumlah itu sekitar $25 \%$ dari total pengaduan di bidang pendidikan sebanyak 1.480 kasus. Bullying yang disebut KPAI sebagai bentuk kekerasan di sekolah mengalahkan tawuran pelajar, diskriminasi pendidikan, ataupun aduan pungutan liar (Republika.co.id., 2015).

Pada awal tahun 2015, bermunculan kasus-kasus bullying di kalangan remaja yang semakin memprihatinkan. Media sedang menyoroti kasus kekerasan yang terjadi di sebuah rumah kos di Bantul, Yogyakarta. Seorang siswi diberitakan mengalami penganiayaan oleh teman sebayanya. Siswi tersebut disekap selama satu malam dan dianiaya dengan cara dipukuli, rambutnya digunting hingga hampir botak, disundut rokok, dsb. (Jawaban.com., 2015).

Kasus lainnya, dialami oleh $N$, seorang anak yang diberitakan pergi dari sekolah dan tidak kembali ke rumah karena kerap mendapatkan perlakuan buruk oleh teman sebayanya di sekolah. $N$ mengaku pergi karena tidak tahan oleh perlakuan temannya. Ibu dari $N$ mengaku 
anaknya sempat diinjak, diludahi, bahkan 'dijambak' oleh teman perempuannya. $N$ ditemukan oleh polisi setelah hilang selama satu minggu (Andini, 2015).

Kasus bullying yang kerap terjadi dalam dunia pendidikan di Indonesia semakin memprihatinkan. Hasil kajian Konsorsium Nasional Pengembangan Sekolah Karakter tahun 2014 menyebutkan, hampir di setiap sekolah di Indonesia ada kasus bullying, meskipun hanya berupa bullying verbal dan psikologis/mental. Melihat kompleksnya kasus-kasus bullying yang ada, Susanto selaku Ketua Konsorsium Nasional Pengembangan Sekolah Karakter menilai bahwa Indonesia sudah masuk kategori "darurat bullying di sekolah", oleh karena itu perlu segera dilakukan intervensi (Beritasatu.com., 2015).

Hawkins, Pepler, dan Craig (2001) menyampaikan bahwa perilaku bullying bisa menjadi semakin meningkat karena kehadiran orang lain yang menyaksikan dan berada di lokasi saat peristiwa terjadi. Kehadiran orang lain saat terjadi peristiwa bullying dikenal dengan istilah bystander. Kehadiran bystander pada peristiwa bullying menjadi sebuah penguatan dan dukungan bagi pelaku. Penguatan pada perilaku bullying juga bersumber dari status sosial di kalangan sebaya sebab dapat meningkatkan popularitas pelakunya. Fonagy dkk. (2009) mengemukakan bahwa bystander yang hadir pada peristiwa bullying berperan sebagai audiens yang membuat sebuah "teater" untuk menyaksikan pertunjukan pelaku (Lenthall, 2003). Penelitian kualitatif Ardianti (2009) menemukan bahwa perasaan berkuasa menjadi salah satu alasan mengapa siswa melakukan bullying. Pelaku bullying merasa bangga dianggap hebat dan ditakuti oleh siswa lain yang melihatnya menindas. Perilaku bullying pada remaja sebagai upaya mereka mendapatkan perhatian 'tertentu' dari teman sebaya (bystander) dapat memicu terulangnya perilaku tersebut di sekolah. Sehingga penelitian ini ditujukan untuk memperoleh informasi tentang efek persepsi pelaku bullying pada bystander terhadap intensitas bullying di sekolah.

Secara fisik, pelaku bullying tidak hanya didominasi oleh anak yang berbadan besar dan kuat, anak bertubuh kecil maupun sedang yang memiliki dominasi yang besar secara psikologis di kalangan teman-temannya juga dapat menjadi pelaku bullying. Alasan yang paling jelas mengapa seseorang menjadi pelaku bullying adalah bahwa pelaku bullying merasakan kepuasan apabila ia "berkuasa" di kalangan teman sebayanya. Selain itu, tawa teman-teman sekelompoknya saat ia mempermainkan korban memberikan penguatan terhadap perilaku bullying (SEJIWA, 2008). Ardianti (2009) menemukan bahwa selain perasaan berkuasa, ada beberapa hal yang menyebabkan seseorang menjadi pelaku bullying di sekolah, diantaranya; faktor penampilan korban, lingkungan, pengalaman masa lalu, perasaan iri, dan latar belakang keluarga.

Perilaku bullying tidak bisa dibiarkan sebab menimbulkan dampak negatif pada siswa yang menjadi korban. Rigby (1999) mengemukakan bahwa anak yang menjadi korban bullying akan merasa terganggu secara psikologis, seperti gugup, cemas, kurang tidur, takut, tidak mau melakukan apapun, membenci sekolah dan merasa stres setiap pagi ketika harus ke sekolah. Adapun secara fisik akan terlihat anak mengeluh sakit di bagian tertentu seperti di kepala, lutut, kaki, atau bahu. Bahkan bisa sampai demam dan muntah. Rigby (1999) mengemukakan bahwa untuk menetapkan tingkatan atau intensitas perilaku bullying, perlu diperhatikan tiga hal, yakni: Pertama, jenis perilaku bullying. 
Jenis perilaku bullying ada berbagai macam, misalnya berupa bullying verbal dengan menghina, mencaci maki, ataupun bullying fisik dengan memukul, menjambak, menampar, dan bullying gestural dengan memandang sinis atau menjauhi; Kedua, durasi terjadinya bullying. Durasi bullying dapat diketahui dengan menentukan periode waktu yang digunakan dalam melakukan bullying. Periode bullying digolongkan dalam tiga kategori, yakni: (1) Bullying kategori rendah, terjadi dengan periode yang singkat yakni 1-8 hari dalam sebulan, dengan bentuk perilaku berupa ejekan, pemberian julukan yang buruk, dan pengucilan sewaktu-waktu. Kebanyakan perilaku bullying di sekolah berada dalam tingkatan ini. (2) Bullying kategori sedang, terjadi dengan periode yang cukup lama yakni 9-16 hari dalam sebulan, dengan bentuk perilaku berupa pelecehan dan penghinaan yang sistematik, dan (3) Bullying kategori tinggi, terjadi dengan periode yang panjang atau sangat lama dan melibatkan intimidasi, tekanan yang kejam dan intens; dan Ketiga, frekuensi bullying. Frekuensi terjadinya bullying, misalnya harian, mingguan atau sangat sering. Coloroso (2006) menyatakan bahwa bystander dalam kasus bullying adalah orang lain atau saksi yang ada saat kasus bullying terjadi selain pelaku dan korban. Penelitian Pepler dan Craig (2000) menemukan bahwa teman-teman sebaya hadir sebagai bystander pada $85 \%$ situasi bullying sehingga insiden tersebut tidak hanya berpengaruh pada pelaku dan korban melainkan juga pada individuindividu yang menyaksikan bullying dan individu-individu yang mendengar mengenai kemunculan perilaku tersebut. Hawkins, Pepler, dan Craig (2001) mengemukakan bahwa kehadiran bystander dalam kasus bullying dianggap penting sebab pelaku memulai serangan ketika rekan-rekan sebaya hadir dalam kasus bullying di sekolah. Penelitian Caravita, DiBlasio, dan Salmivalli (2009) menunjukkan bahwa pelaku bullying menganggap perilaku mereka dapat membantu meningkatkan status mereka dalam kelompok teman sebaya. Penelitian telah menunjukkan bahwa anak-anak yang agresif, termasuk pengganggu (bullies) dianggap sebagai orang yang dingin, kuat, dan populer bahkan dalam kelompok sebaya utama, sehingga pelaku menginginkan status tersebut.

Salmivalli dkk. (1996) mengemukakan bahwa dalam kasus bullying terdapat beberapa peran yang terjadi, diantaranya pelaku, korban, penonton yang memberi dukungan, penonton yang diam saja dan penonton yang menolong korban. Hansen (2013) mengemukakan bahwa perilaku bullying seringkali bergantung pada reaksi pengamat (bystander) yaitu pengamat yang pasif atau pengamat yang mendukung dengan menyoraki. Pelaku bullying kadang tidak menyadari motivasi ini namun menikmati perhatian dan rasa berkuasa tersebut. Skinner (1938) menganalisis bahwa sebuah respons dapat menghasilkan konsekuensi "reinforcement", memperkuat perilaku dan meningkatkan kemungkinan terjadinya respons di masa yang akan datang. Graham dan Bellmore (2007) menyatakan bahwa pelaku bullying memiliki rasa percaya diri dan merasa paling kuat, mereka menikmati status sosial yang tinggi dan dipandang sebagai orang popular di kalangan teman sebayanya.

Coloroso (2006) mengemukakan istilah tiga mata rantai penindasan. Pertama, bullying terjadi karena ada pihak yang menindas, kedua ada penonton yang diam atau bahkan mendukung, dan ketiga, adanya pihak yang dianggap lemah juga menganggap dirinya sebagai pihak yang lemah. Berdasarkan teori tersebut digam- 
barkan bahwa dalam peristiwa bullying ada pembagian peran dari tiga pihak utama, yakni pelaku, korban, dan bystander. Thornberg dan Jungert (2013) mengemukakan bahwa temuan dari studi observasional menunjukkan bahwa bystander jarang bertindak dengan cara membela korban, hasil penelitiannya terhadap 347 remaja menunjukkan bahwa remaja sebagai bystander dalam peristiwa bullying menunjukkan bahwa moral disengagement berhubungan positif terhadap perilaku pro bully, respons yang tidak sesuai dengan nilai moral dimana seharusnya mereka bertindak untuk menolong atau defender.

Pepler dan Craig (2000) mengemukakan beberapa pengaruh teman-teman sebaya yang melihat aktivitas bullying; (1)Teman sebaya terlibat dalam situasi bullying karena hasrat ingin menyerang yang ditimbulkan dari melihat aktivitas bullying. Hal tersebut menjadi dorongan bagi pelaku untuk menyerang korban, (2) Perhatian positif; keberpihakan, peniruan, rasa hormat, dan ketakutan untuk melawan yang terjadi pada penonton akan semakin memperkuat dominasi pelaku; (3) Penonton yang tidak memberikan empati atau pertolongan, bahkan memberikan perhatian yang negatif dengan bersikap menyalahkan korban sebagai "pemicu" perlakuan bullying terhadapnya; (4) Siswasiswa yang berpihak pada pelaku akan semakin agresif dan tidak sensitif terhadap penderitaan korban. Mereka mengharapkan "perlindungan" dari pelaku dan status sosial yang lebih tinggi. Pada akhirnya akan terbentuk kelompok yang solid dan mampu melakukan aktivitas terencana; dan (5) Penegasan risiko bagi siswa-siswa yang berpihak pada korban, mereka bisa menjadi korban berikutnya.

Hipotesis yang diajukan pada penelitian ini adalah bahwa diduga ada pengaruh positif persepsi pada bystander terha- dap intensitas bullying pada siswa SMP. Semakin baik persepsi pada bystander maka semakin tinggi intensitas bullying dan semakin buruk persepsi pada bystander maka semakin rendah intensitas bullying siswa SMP.

\section{Metode}

Variabel bebas dalam penelitian ini adalah persepsi pada bystander. Persepsi pada bystander adalah anggapan pelaku bullying bahwa teman-teman sebaya yang melihat aksinya akan takut dan segan sehingga membiarkan bahkan mendukung perilaku mengganggunya di sekolah. Persepsi pada bystander diukur dengan menggunakan skala persepsi pada bystander yang dikonstruksi berdasarkan aspek pengaruh teman sebaya terhadap pelaku bullying yang dikemukakan oleh Pepler dan Craig (2000), meliputi dorongan untuk menyerang, perhatian positif, perhatian negatif, perlindungan, dan penegasan risiko. Semakin tinggi jumlah skor yang diperoleh subjek maka semakin besar persepsi pelaku bullying pada teman sebaya, namun bila skor yang diperoleh rendah maka semakin rendah persepsi pelaku bullying pada teman sebaya.

Variabel terikat dalam penelitian ini adalah intensitas bullying. Intensitas bullying adalah seberapa lama dan seringnya perilaku bullying siswa terulang pada teman sebaya di sekolah. Intensitas dilihat dari frekuensi melakukan bullying dalam durasi seminggu terakhir. Skala intensitas bullying diadaptasi dari skala yang dikembangkan oleh Orpinas dan Frankowski (2001) semakin tinggi skor yang diperoleh subjek maka semakin intens subjek melakukan bullying dan bila skor yang diperoleh subjek rendah maka semakin rendah intensitas perilaku bullying. 
Populasi dalam penelitian ini adalah siswa SMP di Makassar yang berjumlah 88 orang. Teknik pengambilan sampel yang digunakan adalah purposive sampling dimana karakteristik sampel telah ditetapkan berdasarkan ciri dan sifat populasinya (Winarsunu, 2006). Subjek dalam penelitian ini adalah individu yang pernah melakukan bullying, sebanyak 48 siswa SMP di Makassar yang terpilih setelah mengisi survei untuk mengungkap perilaku bullying. Adapun kriteria subjek dalam penelitian ini adalah: (1) Remaja dengan rentang usia 10-15 tahun, (2) Pernah melakukan bullying, dan (3) Sedang menuntut ilmu ditingkat SMP di Makassar.

\section{Skala persepsi pada bystander}

Skala persepsi pada bystander disusun berdasarkan pengaruh teman sebaya yang mengetahui/melihat aktivitas bullying yang dikemukakan oleh Pepler dan Craig (2000) berupa dorongan untuk menyerang, perhatian positif, perhatian negatif, perlindungan, dan penegasan risiko. Skala persepsi pada bystander dikonstruksi sendiri oleh peneliti dengan empat alternatif jawaban untuk setiap aitem, yaitu; Sangat Sesuai (SS), Sesuai (S), Tidak Sesuai (TS), dan Sangat Tidak Sesuai (STS ). Skala persepsi pada bystander telah divalidasi oleh professional judgement dan memiliki alpha cronbach sebesar 0,712 .

\section{Skala Intensitas bullying}

Skala intensitas bullying terdiri atas dua aspek yakni, aspek durasi dan aspek frekuensi bullying. Aspek durasi bullying dibuat berupa isian dengan bentuk pertanyaan sedangkan skala frekuensi bullying yang digunakan dalam penelitian ini diadaptasi dari Measuring bullying, victimization, preparation, and bystander: A compendium of assessment tools yang dikembangkan oleh Orpinas dan Frankowski (2001) terdiri dari 10 aitem untuk mengungkap berapa kali subjek melakukan bullying dalam tujuh hari terakhir. Skala intensitas bullying yang digunakan berlandaskan indikator intensitas bullying dari Rigby (2002). Proses adaptasi skala menggunakan teknik back translation. Skala intensitas bullying yang diadaptasi memiliki alpha cronbach sebesar 0,829 .

Data yang terkumpul dianalisis dengan analisis regresi sederhana dengan menggunakan bantuan program analisis Statistical Product and Service Solution (SPSS) for windows 16.0 version.

\section{H a s i 1}

Berdasarkan hasil penelitian terhadap 48 subjek yang berpartisipasi pada penelitian, dengan rentang usia 12 hingga 15 tahun dengan kategori usia terbanyak adalah subjek dengan usia 13 tahun (56,25\%). Subjek terdiri dari $27(56,25 \%)$ berjenis kelamin laki-laki dan 21 (43,75\%) berjenis kelamin perempuan. Dilihat dari durasi bullying, mayoritas subjek yakni sebanyak 23 orang $(47,91 \%)$ telah melakukan bullying lebih dari satu bulan lamanya. Karakteristik 48 subjek penelitian terlihat pada Tabel 1.

Berdasarkan hasil uji hipotesis, diperoleh besarnya kolerasi atau hubungan antara persepsi pada bystander dengan intensitas bullying adalah 0,343 dengan nilai $r$ dan signifikansi atau $p$ sebesar 0,017 dengan jumlah subjek 48 siswa pelaku bullying di SMP di Makassar. Kaidah yang digunakan dalam menentukan hipotesis adalah apabila nilai $p<0,05$ maka hipotesis alternatif (Ha) diterima dan hipotesis nihil (Ho) ditolak. Sehingga dapat disimpulkan bahwa ada pengaruh positif persepsi pelaku bullying terhadap intensitas bullying pada siswa SMP di Makassar. Tingkat koefisien korelasi berdasarkan data yang 
diperoleh berkisar antara 0,20 hingga 0,39 maka tingkat pengaruh berada pada kategori rendah. Nilai koefisien determinasi $(r$ square) dari hasil analisis kedua variabel menunjukkan nilai sebesar 0,118 yang berarti, $11,8 \%$ intensitas bullying dapat dijelaskan oleh persepsi pelaku bullying terhadap bystander, sedangkan sisanya $88,2 \%$ dijelaskan oleh faktor lain yang tidak disertakan dalam penelitian ini seperti faktor penampilan korban, perasaan berkuasa, pengalaman masa lalu perasaan iri, dan latar belakang keluarga. Pengujian hipotesis dilakukan dengan menggunakan teknik analisis regresi sederhana. Hasil uji hipotesis ditunjukkan pada Tabel 2.

Hasil analisis data menunjukkan bahwa terdapat pengaruh positif antara persepsi pelaku bullying terhadap intensitas bullying pada siswa SMP di Makassar. Festinger, (1957); Cooper, dan Fazio (1984) sepakat bahwa pelaku bullying mempersepsikan bystander sebagai pendukung atas perilakunya dan dukungan tersebut menjadi sebuah reward. CQ Researcher (2005) mengemukakan bahwa bystander berperan penting dalam kasus bullying. Bystander yang diam saja atau tidak memperdulikan perlakuan bullying yang dilakukan temannya membuat pelaku merasa terdukung dan menganggap biasa hal tersebut, namun ketika reaksi bystander bergerak membantu korban, maka pelaku akan merasa gagal karena tidak ada yang menerima perilakunya tersebut.

Tabel 1

Karakteristik subjek penelitian

\begin{tabular}{|c|c|c|c|}
\hline No. & Karakteristik & Jumlah & Persentase (\%) \\
\hline \multirow[t]{5}{*}{1.} & Usia: & & \\
\hline & 12 tahun & 2 & $4,166 \%$ \\
\hline & 13 tahun & 27 & $56,25 \%$ \\
\hline & 14 tahun & 18 & $37,5 \%$ \\
\hline & 15 tahun & 1 & $2,083 \%$ \\
\hline & Jumlah & 48 & $100 \%$ \\
\hline \multirow[t]{3}{*}{2.} & Jenis Kelamin: & & \\
\hline & Laki-laki & 27 & $56,25 \%$ \\
\hline & Perempuan & 21 & $43,75 \%$ \\
\hline & Jumlah & 48 & $100 \%$ \\
\hline \multirow[t]{6}{*}{3.} & Durasi bullying: & & \\
\hline & 1-8 hari & 18 & $37,5 \%$ \\
\hline & 9-16 hari & 5 & $10,41 \%$ \\
\hline & 17-30 hari & 2 & $4,166 \%$ \\
\hline & $>30$ hari & 23 & $47,91 \%$ \\
\hline & Jumlah & 48 & $100 \%$ \\
\hline
\end{tabular}

Catatan: Durasi bullying adalah berapa lama subjek telah melakukan bullying

Tabel 2

Hasil uji hipotesis penelitian

\begin{tabular}{ccccc}
\hline Variabel & $\boldsymbol{R}$ & $\boldsymbol{P}$ & $\boldsymbol{r}$ Square & Keterangan \\
\hline $\begin{array}{c}\text { Persepsi pada } \\
\text { bystander }\end{array}$ & & & & \\
\hline $\begin{array}{c}\text { Intensitas } \\
\text { bullying }\end{array}$ & 0,343 & 0,017 & 0,118 & $\begin{array}{c}\text { Signifikan } \\
(p<0,05)\end{array}$ \\
\hline
\end{tabular}




\section{Diskusi}

Berdasarkan hasil penelitian, diketahui bahwa pengaruh persepsi pelaku bullying terhadap kehadiran bystander adalah $11,8 \%$. Artinya, $11,8 \%$ persepsi pelaku bullying terhadap kehadiran bystander dapat menjelaskan penyebab terulangnya perilaku bullying di sekolah. Terulangnya perilaku bullying di sekolah disebabkan kurangnya kepedulian moral dari bystander untuk membantu korban.Temuan dari studi observasional menunjukkan bahwa bystander jarang bertindak dengan cara membela korban. Respons bystander cenderung mengalami pelepasan moral sehingga tampak berperilaku pro bully (Thornberg \& Jungert, 2013). Pengaruh yang ditemukan dalam penelitian ini hanya dari sudut pandang pelaku terhadap penonton (bystander). Hal lain yang turut memicu terjadinya bullying adalah beberapa faktor lain yang terungkap dalam penelitian kualitatif Ardianti (2009) seperti penampilan korban, perasaan berkuasa, pengalaman masa lalu, perasaan iri, dan latar belakang keluarga.

Meskipun koefisien pengaruh kehadiran bystander tergolong rendah dalam penelitian ini $(r=0,343)$, namun hal ini berperan dalam memperkuat atau memicu terulangnya perilaku bullying di sekolah. Hansen (2013) mengemukakan bahwa perilaku bullying seringkali bergantung pada reaksi pengamat (bystander) yaitu pengamat yang pasif atau pengamat yang mendukung dengan menyoraki. Pelaku bullying kadang tidak menyadari motivasi ini namun menikmati perhatian dan rasa berkuasa tersebut. Maslow (1970) menjelaskan bahwa salah satu motivasi yang menjadi dasar seseorang berperilaku adalah kebutuhan dasar. Salah satu kebutuhan dasar manusia adalah aktualisasi diri (self actualization). Aktualisasi diri sebagai kesempatan bagi seseorang untuk mengembangkan potensi dirinya sehingga berubah menjadi kemampuan nyata baik itu positif maupun negatif. Berdasarkan teori tersebut dapat dijelaskan bahwa pela$\mathrm{ku}$ bullying mengaktualisasikan diri sebagai remaja untuk menyalurkan potensi berlebih yang dirasakan berupa tindakan negatif sebab menyakiti orang lain dengan sengaja

Secara fisik, pelaku bullying tidak hanya didominasi oleh anak yang berbadan besar dan kuat. Anak bertubuh kecil yang memiliki dominasi yang besar secara psikologis di kalangan teman-temannya juga dapat menjadi pelaku bullying. Alasan yang paling jelas mengapa seseorang menjadi pelaku bullying adalah merasakan kepuasan apabila ia "berkuasa" di kalangan teman sebayanya (Yayasan SEJIWA, 2008).

Adapun gambaran subjek pelaku bullying dalam penelitian ini sebanyak 48 siswa yang terdiri dari 27 laki-laki (56,25\%) dan 21 perempuan (43,75\%). Usia subjek berkisar antara 11 hingga 15 tahun, subjek menempuh jenjang pendidikan di SMP sebagai siswa kelas dua. Berdasarkan pengamatan peneliti selama berada dalam lingkungan sekolah, baik siswa maupun siswi cenderung bersikap agresif dalam bentuk menghina, mendorong, dan sebagainya. Hasil survei yang dilakukan pada subjek menunjukkan bahwa sebesar 83,7\% siswa menghina dengan nama julukan, $53,48 \%$ menjahili, 32,55\% mengancam akan melakukan hal buruk, 48,8\% menjadikan teman bahan tertawaan, 53,48\% mengucilkan, 32,55\% merusak barang milik teman, 62,79\% memukul, 65,11\% tidak bicara padanya, $25,5 \%$ menulis sesuatu yang buruk tentangnya, 44,1\% 'menggunjingkan', dan 65,11\% mendorong korban.

Deskripsi subjek penelitian menunjukkan bahwa $47,91 \%$ subjek penelitian 
telah melakukan bullying dengan lama waktu satu bulan keatas sehingga kategori subjek kelompok ini tergolong intens melakukan bullying. Sejalan dengan hasil kuesioner tersebut, frekuensi bullying siswa dalam durasi seminggu terakhir menunjukkan hasil kategorisasi skor intensitas bullying pada tingkat sedang. Adapun mean hipotetik skala intensitas bullying adalah sebesar 11,8 lebih rendah dari mean empirik sebesar 30 sehingga disimpulkan bahwa intensitas bullying tergolong tinggi. Rigby (2002) menjelaskan bahwa intensitas bullying dalam kategori tinggi, terjadi dengan durasi yang panjang atau sangat lama, melibatkan intimidasi, tekanan yang kejam dan intens. Bullying kategori tinggi melibatkan serangan fisik yang cukup ekstrim seperti memukul, menendang, melukai dengan senjata dan sebagainya, namun bisa juga melibatkan aksi non-fisik seperti pengasingan total dari kelompok, fitnah yang kejam dan sarkasme yang berlebihan.

Turmudi (2009) mengemukakan bahwa perilaku bullying yang terjadi di sekolah bukanlah suatu hal yang bisa dibiarkan atau dianggap wajar. Upaya untuk memperkecil atau bahkan meniadakan tindak kekerasan di sekolah harus terus dilakukan, termasuk mengurangi kehadiran orang-orang yang mendukung dan menumbuh suburkan perilaku tersebut. Konsep sekolah yang ramah pada anak/ siswa merupakan hal yang sangat mendesak untuk diterapkan. Segenap stakeholder yang peduli dengan pendidikan dan pembentukan sikap mental atau akhlak peserta didik yang terpuji harus bersinergi untuk mewujudkan cita-cita mulia ini. National Education Association (2003) menjelaskan bahwa kasus bullying memberi dampak signifikan pada siswa dan keluarganya. Dalam penanganannya, kepala sekolah tidak hanya berinteraksi dengan pelaku maupun korban, namun juga harus bekerjasama dengan guru atau staf lain untuk mengurangi bullying.

Kelemahan dalam penelitian ini adalah hasil koefisien regresi yang diperoleh tergolong rendah, hal tersebut kemungkinan terjadi karena bias desirabilitas, dan karakteristik subjek yang masih belia, sehingga kurang sungguh-sungguh dalam mengisi skala yang diberikan (Ruane, 2013).

\section{Kesimpulan}

Terdapat pengaruh positif persepsi pelaku bullying pada bystander terhadap intensitas bullying siswa SMP. Semakin tinggi persepsi pada bystander, maka semakin intens siswa melakukan bullying di sekolah. Sebaliknya, semakin rendah persepsi pada bystander maka semakin rendah intensitas bullying siswa di SMP. Sumbangan efektif persepsi pada bystander adalah $11,8 \%$ sedangkan sisanya, $88,2 \%$ dipengaruhi oleh faktor-faktor lain seperti faktor penampilan korban, perasaan berkuasa, pengalaman masa lalu perasaan iri, dan latar belakang keluarga.

\section{Saran}

Berdasarkan hasil penelitian dan kesimpulan yang telah diuraikan sebelumnya, maka dapat dikemukakan beberapa saran sebagai berikut: (1) Kepada dinas pendidikan daerah agar berkoordinasi dengan pihak sekolah dalam menerapkan pendidikan karakter yang berisi penanaman nilai-nilai moral sebagai salah satu wujud dari penanganan bullying yang disarankan oleh KPAI. (2) Kepada pihak sekolah agar mengintensifkan berbagai kegiatan positif seperti ekskul dan kegiatan sejenis yang mampu mengembangkan kemampuan anak dan mengarahkan anak untuk meningkatkan potensi diri yang 
dimilikinya. (3) Kepada orang tua maupun keluarga untuk berperan dalam mengawasi dan memberi pelajaran moral pada anak berupa edukasi agar anak terhindar dari perilaku negatif yang akan berdampak buruk bagi dirinya maupun lingkungannya. (4) Kepada siswa yang terlibat dalam situasi bullying di sekolah, agar tidak membiarkan temannya menjadi korban, sehingga diharapkan agar siswa lebih peka melihat situasi ini dan mengambil peran dalam menghentikan episode bullying di lingkungannya, dan (5) Kepada semua pihak yang peduli terhadap pendidikan di Indonesia, perlu mengambil peran dalam membantu mencerdaskan moral anak bangsa dengan upaya memperkecil atau meniadakan berbagai bentuk tindak kekerasan antar pelajar.

\section{Kepustakaan}

Andini, R. (2015). Sebelum Hilang, Nadhira Sering di-Bully. (online). Diunduh dari: http://news.okezone.com/read/2015/03 /12/338/1117577/sebelum-hilangnadhira-sering-di-bully. tanggal 26 Maret 2015.

Ardianti, C. (2009). Identifikasi Faktor-faktor yang Mempengaruhi Bullying. (Skripsi tidak dipublikasikan). Semarang: Fakultas Psikologi Universitas Katolik Soegijapranata Semarang. Diunduh dari: http://eprints.unika.ac.id/ 17550/1/03.40.0097_Clementia_Ardiant i.pdf. tanggal 11 Juli 2013.

Beritasatu.com. (2014). Indonesia Masuk kategori Darurat Bullying di Sekolah. (online). Diunduh dari: http://www. beritasatu.com/gaya-hidup/219515indonesia-masuk-kategori-daruratbullying-di-sekolah.html

Caravita, S., DiBlasio, P., \& Salmivalli, C. (2009). Unique and interactive effects of empathy and social status on inovlvement in bullying. Social Development, 18,140-163.

Coloroso, B. (2006). Penindas, Tertindas, dan Penonton; Resep Memutus Rantai Kekerasan Anak dari Prasekolah hingga SMU. Jakarta: Serambi Ilmu Pustaka.

Cooper, J. \& Fazio, R. H. (1984). A new look at dissonance theory. In Berkowitz L.(Ed.), Advances in experimental social psychology. Academic Press. New York.

CQ Researcher. (2005). Bullying: Are schools doing enough to stop the problem. The CQ Researcher, 15(4), 103-123.

Festinger, L. (1957). A theory of cognitive dissonance, Stanford University Press, California

Fonagy P., Twemlow S. W., Vernberg, E. M., Nelson, J. M., Dill, E. J., Little, T. D., \& Sargent J. A. (2009). A cluster randomized controlled trial of childfocused psychiatric consultation and a school systems-focused intervention to reduce aggression, 50(5), 607-16. http://dx.doi.org/10.1111/j.14697610.2008.02025.x.

Graham, S., \& Bellmore, A., D. (2007). Peer Victimitation and Mental Health During Early Adolescence. Theory into Practice, 46, 138-146.

Hansen, B. (2013). Bullies and Bystanders. Diunduh dari: http://www.yourtango. com/experts/brock-hansen/bulliesand-bystanders-expert tanggal 11 juli 2013

Hawkins, D. L., Pepler, D., \& Craig, W. M. (2001). Peer interventions in playground bullying. Social Development, 10, 512-527.

Huneck, A. (2007). Handout Workshop Nasional: Intervensi Efektif Untuk Mengurangi Bullying di Sekolah-Sekolah. 
Handout. Dipresentasikan pada 28 April 2007 di hotel J.W. Marriot.

Jawaban.com. (2015). Darurat Bullying yang Semakin Mencekam. (online). Diunduh dari: http://www.jawaban.com/read/ article/id/2015/02/26\%2010:00:00/93/15 0226112213/Darurat-Bullying-yangSemakin-Mencekam. tanggal 26 Maret 2015

Lenthall, D. A. (2003). Bystander behavior as an influence on bullying in high schools. Thesis. Faculty of Arts: Deakin University.

Maslow, A., H. (1970). Motivation and Personality(2 ${ }^{\text {nd }}$ edition). New York: Harper.

National Education Association.(2003). National bullying awareness campaign. (online). Diunduh dari: http://www. nea.org/schoolsafety/bullying.html

National Association of Elementary School Principals. (2013). "Put a stop to bullying in your school.(online). Diunduh dari: http://www.naesp.org/bullyingprevention-resources

Orpinas, P., \& Frankowski, R. (2001). The Aggression Scale: A self-report measure of aggressive behavior for young adolescents. Journal of Early Adolescence, 21, 50-67.

Pepler D. J., \& Craig W. M. (200). Making a difference in bullying. LaMarsh Report 59. Toronto: York University.

Republika (2014). Aduan bullying tertinggi. (online). Diunduh dari: http://www. republika.co.id/berita/koran/halaman1/14/10/15/ndh4sp-aduan-bullyingtertinggi

Riauskina, Indira, I., Djuwita, R., \& Soesetio, S., R. (2005). "Gencetgencetan" di Mata Siswa/Siswi Kelas 1 SMA: Naskah Kognitif Tentang Arti, Skenario, dan Dampak "Gencet- gencetan". Jurnal Psikologi Sosial/JPS, 12(1), 2-13.

Rigby, K. (1999). What harm does bullying do?. Paper presented at the Children and Crime: Victims and Offenders Conference convened by the Australian Institute of Criminology and held in Brisbane.

Rigby, K. (2002). New Perspectives on Bullying. Jessica Kingsley Publishers: London

Ruane, M. J. (2013). Metode penelitian: Panduan Riset Ilmu Sosial. Bandung: Nusa Media.

Salmivalli, C., Lagerspetz, K., Bjorkqvist, K., Osterman, K., \& Kaukiainen, A. (1996). Bullying as a Group Process: Participant Roles and Their Relations to Social Status Within The Group. Aggressive Behavior, 22(1), 1-15. Diunduh dari: http://onlinelibrary. wiley.com/journal/10.1002/(ISSN)10982337

Simbolon, M. (2012). Perilaku bullying pada mahasiswa berasrama. Jurnal Psikologi. 39(2), 223-243.

Skinner, B., F. (1938). The Behavior of Organisms. New York: Appleton-CenturyCrofts.

Susanti, I. (2006). Bullying Bikin Anak Depresi dan Bunuh Diri. (online). Diunduh dari: http://www.kpai.go.id/ mn_access.php?to=2-artikel\&sub=kpai -2-artikel_bd.html. tanggal 10 Januari 2013.

Thornberg, R., \& Jungert, T. (2013). Bystander behavior in Bullying Situations: Basic Moral Sensitivity, Moral disengagement, and defender self-efficacy. Journal of Adolescence, 3(36), 475-483.

Turmudi. (2009). Mengenali kekerasan dalam pendidikan dan upaya meniadakannya atau memperkecil risiko tindak kekerasan. 
HALIMAH, DKK.

(online). Jurnal Pendidikan. Dipresentasikan dalam Seminar Nasional di Universitas Tanjung Pura, dengan Tema Kekerasan dalam Pendidikan, 18 Mei 2009, Pontianak.
Winarsunu, T. (2006). Statistik dalam Penelitian Psikologi dan Pendidikan. Malang: UMM Press.

Yayasan Semai Jiwa Amini (SEJIWA). (2008). Bullying Mengatasi Kekerasan di Sekolah dan Lingkungan Sekitar Anak. Jakarta: Grasindo. 